\title{
Intraparenchymal ultrasound application and improved distribution of infusate with convection-enhanced delivery in rodent and nonhuman primate brain
}

\author{
Yui Mano, MD, ${ }^{1}$ Ryuta Saito, MD, PhD, ${ }^{1}$ Yoichi Haga, MD, PhD, ${ }^{2}$ Tadao Matsunaga, PhD, ${ }^{3}$ \\ Rong Zhang, MD, PhD, ${ }^{1}$ Masashi Chonan, MD, ${ }^{1}$ Shinya Haryu, MD, ${ }^{1}$ Takuhiro Shoji, MD, ${ }^{1}$ \\ Aya Sato, BE, ${ }^{1}$ Yukihiko Sonoda, MD, PhD, ${ }^{1}$ Noriko Tsuruoka, MS, ${ }^{2}$ Keisuke Nishiyachi, BS, ${ }^{2}$ \\ Akira Sumiyoshi, PhD, ${ }^{4}$ Hiroi Nonaka, MA, ${ }^{4}$ Ryuta Kawashima, MD, PhD, ${ }^{4}$ and \\ Teiji Tominaga, MD, PhD'
}

${ }^{1}$ Department of Neurosurgery, Tohoku University Graduate School of Medicine; ${ }^{2}$ Department of Biomedical Engineering, Tohoku
University Graduate School of Biomedical Engineering; ${ }^{3}$ Tohoku University Micro System Integration Center ( $\mu$ SIC); and
${ }^{4}$ Department of Functional Brain Imaging, Institute of Development, Aging and Cancer, Tohoku University, Sendai, Miyagi, Japan

OBJECTIVE Convection-enhanced delivery (CED) is an effective drug delivery method that delivers high concentrations of drugs directly into the targeted lesion beyond the blood-brain barrier. However, the drug distribution attained using CED has not satisfactorily covered the entire targeted lesion in tumors such as glioma. Recently, the efficacy of ultrasound assistance was reported for various drug delivery applications. The authors developed a new ultrasoundfacilitated drug delivery (UFD) system that enables the application of ultrasound at the infusion site. The purpose of this study was to demonstrate the efficacy of the UFD system and to examine effective ultrasound profiles.

METHODS The authors fabricated a steel bar-based device that generates ultrasound and enables infusion of the aqueous drug from one end of the bar. The volume of distribution (Vd) after infusion of $10 \mu \mathrm{l}$ of $2 \%$ Evans blue dye (EBD) into rodent brain was tested with different frequencies and applied voltages: $252 \mathrm{kHz} / 30 \mathrm{~V} ; 252 \mathrm{kHz} / 60 \mathrm{~V} ; 524 \mathrm{kHz} / 13 \mathrm{~V}$; $524 \mathrm{kHz} / 30 \mathrm{~V}$; and $524 \mathrm{kHz} / 60 \mathrm{~V}$. In addition, infusion of $5 \mathrm{mM}$ gadopentetate dimeglumine (Gd-DTPA) was tested with $260 \mathrm{kHz} / 60 \mathrm{~V}$, the distribution of which was evaluated using a 7-T MRI unit. In a nonhuman primate (Macaca fascicularis) study, $300 \mu$ l of $1 \mathrm{mM}$ Gd-DTPA/EBD was infused. The final distribution was evaluated using MRI. Two-sample comparisons were made by Student t-test, and 1-way ANOVA was used for multiple comparisons. Significance was set at $p<$ 0.05 .

RESULTS After infusion of $10 \mu$ l of EBD into the rat brain using the UFD system, the Vds of EBD in the UFD groups were significantly larger than those of the control group. When a frequency of $252 \mathrm{kHz}$ was applied, the $\mathrm{Vd}$ of the group in which $60 \mathrm{~V}$ was applied was significantly larger than that of the group in which $30 \mathrm{~V}$ was used. When a frequency of $524 \mathrm{kHz}$ was applied, the Vd tended to increase with application of a higher voltage; however, the differences were not significant (1-way ANOVA). The Vd of Gd-DTPA was also significantly larger in the UFD group than in the control group $\left(p<0.05\right.$, Student t-test). The volume of Gd-DTPA in the nonhuman primate used in this study was $1209.8 \pm 193.6 \mathrm{~mm}^{3}$. This volume was much larger than that achieved by conventional CED $\left(568.6 \pm 141.0 \mathrm{~mm}^{3}\right)$.

CONCLUSIONS The UFD system facilitated the distribution of EBD and Gd-DTPA more effectively than conventional CED. Lower frequency and higher applied voltage using resonance frequencies might be more effective to enlarge the Vd. The UFD system may provide a new treatment approach for CNS disorders.

http://thejns.org/doi/abs/10.3171/2015.3.JNS142152

KEY WORDS convection-enhanced delivery; ultrasound; drug delivery; blood-brain barrier; central nervous system; Macaca fascicularis; rat; diagnostic and operative techniques

ABBREVIATIONS CED = convection-enhanced delivery; EBD = Evans blue dye; FUS = focused ultrasound; Gd-DTPA = gadopentetate dimeglumine; PBS = phosphatebuffered saline; PZT = lead zirconate titanate; RARE = rapid acquisition with relaxation enhancement; UFD = ultrasound-facilitated delivery; Vd = volume of distribution. SUBMITTED September 16, 2014. ACCEPTED March 30, 2015.

INCLUDE WHEN CITING Published online October 23, 2015; DOI: 10.3171/2015.3.JNS142152. 
$\mathrm{C}$ ONVECTION-ENHANCED delivery (CED), which uses bulk flow, enables the delivery of small and large molecules to clinically significant volumes of targeted tissues, offering an improved volume of distribution (Vd) compared with simple diffusion. ${ }^{3}$ The efficacy of this local infusion technique for treating focal CNS diseases such as brain tumors, 7,8,19,21-23,27,29 neurodegenerative diseases, ${ }^{14,25}$ and spinal cord injury ${ }^{2}$ has recently been demonstrated. However, a recently completed Phase III randomized trial on recurrent glioblastoma (the PRECISE [Phase III Randomized Evaluation of Convection Enhanced Delivery of IL13-PE38QQR with Survival Endpoint] study), which used CED, failed to demonstrate its efficacy. ${ }^{11}$ There was no significant survival difference between a group that received CED administration of cintredekin besudotox and a group that received Gliadel wafers. Unsatisfactory distribution was described as one of the possible explanations for this failure by the PRECISE study group. ${ }^{24}$ The conventional CED method might be insufficient to cover the targeted region, such as a tumor infiltrative lesion in human glioblastoma.

Several reports have already demonstrated the efficacy of ultrasound-assisted drug delivery using focused ultrasound (FUS), ${ }^{4,5,9,15}$ time-reversal acoustics, ${ }^{12,20}$ and combinations with CED methods. ${ }^{13,16}$ They are all promising, but they may have several problems for clinical application.

In this study, we developed a new ultrasound-assisted drug delivery device, the ultrasound-facilitated delivery (UFD) system, which enables robust distribution even at a deep-targeted site. In addition, we investigated the acoustic properties of the newly developed UFD device and its efficacy by comparing the $\mathrm{Vd}$ after delivery using it or conventional CED in rats and nonhuman primates.

\section{Methods}

\section{Assembling the UFD System}

Ring-shaped (outer diameter $20 \mathrm{~mm}$, inner diameter $2 \mathrm{~mm}$, thickness $2 \mathrm{~mm}$ ) piezoelectric material (lead zirconate titanate [PZT]) was used (Fig. 1). A metal rod was placed through the hole of the PZT ring. Conducting wires were soldered at the PZT rims. A brass horn was bonded to the ring-shaped PZT using solder. A hole was drilled at the tip of the brass horn $5 \mathrm{~mm}$ in depth and $2 \mathrm{~mm}$ in diameter. A $4-\mathrm{cm}$ or $15-\mathrm{cm}$ steel bar with a $0.2-\mathrm{mm}$ groove on its side was inserted into the tip of the hole and fixed. The 4-cm steel bar-type UFD system is suitable for rats, and the $15-\mathrm{cm}$ one for nonhuman primates. The ultrasound is generated by the PZT, is transmitted from the horn to the steel bar, and is emitted around the steel bar. The $0.2-\mathrm{mm}$ silicone tube was connected to the syringe placed on a microinfusion pump (BeeHive; Bioanalytical Systems) to control the infusion rate, and the tube was inserted into the side groove of the steel bar; the end of the silicone tube was placed at the tip of the steel bar. This UFD system enables the delivery of ultrasound and infusate simultaneously into the targeted region.

\section{Measuring Resonance Frequencies and Acoustic Pressure In Vitro}

The properties of ultrasound generated by the UFD sys- tem we developed were measured. Frequency characteristics of the UFD system and the relationship between acoustic pressure and applied voltage at resonance frequencies were evaluated. A broadband miniature probe hydrophone (TC4038, Teledyne Reson) was fixed to the bottom of the water pool, and its tip was placed $2 \mathrm{~mm}$ from the tip of the UFD system (Fig. 2A). The function generator (AFG2105, GW Instek) generated a continuous sine wave at each frequency, and its waves were amplified using an amplifier (DC to $10 \mathrm{MHz} ; 05810$ Power Amplifier, Yokogawa Electric Corp.). These amplified waves were applied to the UFD system. The applied waves and output signal of the hydrophone were measured using an oscilloscope (DL716, Yokogawa Electric Corp.).

Measured hydrophone output voltages (V) were converted to acoustic pressure $(\mathrm{Pa})$ by using an acoustic pressure conversion factor. The acoustic pressure conversion factor depends on the properties of the hydrophone.

Acoustic pressures were calculated using the following formula: Acoustic pressure $(\mathrm{Pa})=$ Hydrophone voltage (V)/Acoustic pressure conversion factor (V/Pa). To detect resonance frequencies, the voltage (which was a continuous sine wave) applied to the PZT was fixed at $30 \mathrm{~V}_{\mathrm{p}-\mathrm{p}}$. In this situation, frequencies were changed from $50 \mathrm{kHz}$ to $800 \mathrm{kHz}$. To determine the optimal frequency for an in vivo study, we exhaustively searched resonance frequencies from 50 to $800 \mathrm{kHz}$ in an in vitro setting (Fig. 2A). A previous study suggested that the optimal frequencies for drug delivery to the brain may exist at $<1 \mathrm{MHz},{ }^{18}$ therefore, a range from 50 to $800 \mathrm{kHz}$ was selected. Once the resonance frequency was detected, the applied voltage from the amplifier was changed and hydrophone voltage was recorded. The acoustic pressure at resonance frequencies is approximately proportionate to the applied voltage. These stably observed resonance frequencies were used in a subsequent in vivo study.

\section{Experimental Animals}

A total of 48 male Fischer 344 rats and 1 male cynomolgus monkey (Macaca fascicularis) were used throughout this experiment. Male Fischer 344 rats weighing 200-250 g were purchased from Kumagai-shigeyasu Co., Ltd., and an adult male cynomolgus monkey (3-4 kg) was purchased from Japan SLC, Inc. Prior to assignment to the nonhuman primate study, the imported animal underwent an at least 31-day quarantine period; this was a period that only involved observation. All protocols used for the animal studies were approved by the Institutional Animal Care and Use Committee at Tohoku University Graduate School of Medicine.

\section{Surgery and the UFD Procedures}

In the rat study, under deep isoflurane anesthesia, the animals were placed in a small-animal stereotactic frame (Narishige). Each rat was initially anesthetized with $4 \%$ isoflurane and an air/oxygen mixture (7:3). The isoflurane level was lowered to $2.0 \% \pm 0.5 \%$ during the surgery and infusion. A sagittal incision was made to expose the cranium, followed by a bur hole in the skull positioned at 0.5 $\mathrm{mm}$ anterior and $3 \mathrm{~mm}$ lateral from the bregma and made 

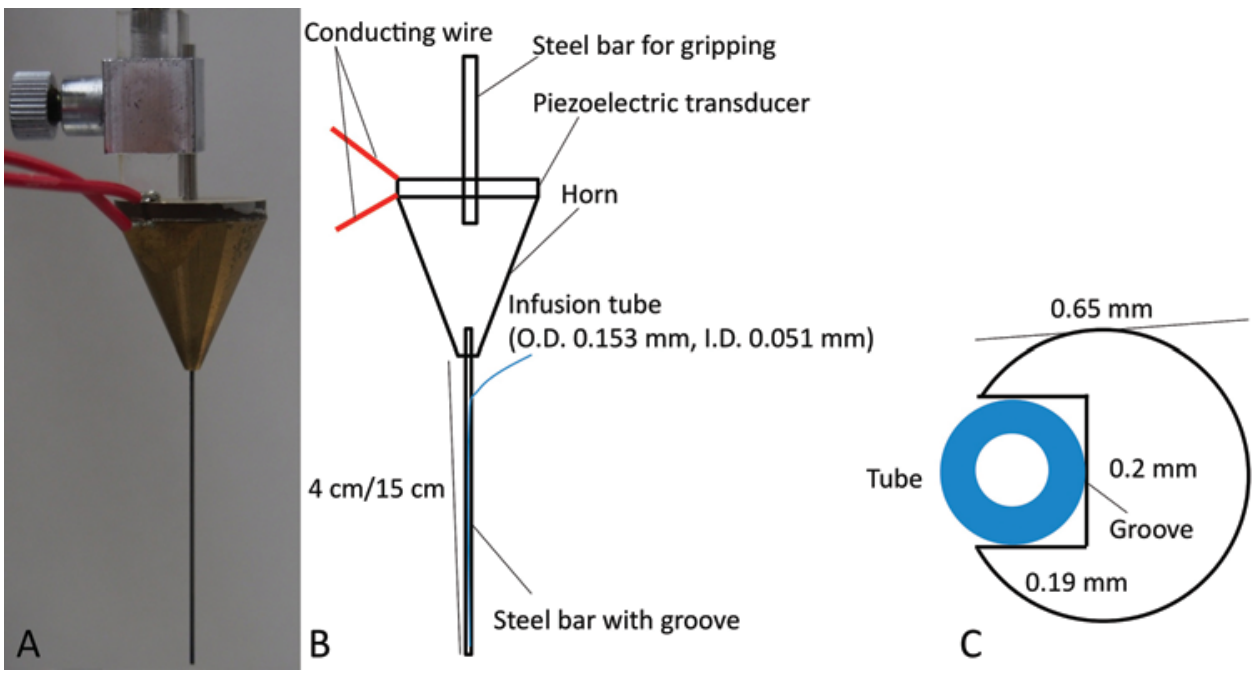

FIG. 1. Photograph (A) and drawing (B) of the UFD system. A piezoelectric transducer generated ultrasound, which was transmitted from the brass horn to the steel bar with a drug infusion tube fixed in the side groove. Two types of device were fabricated: one with a 4-cm steel bar and the other with a $15-\mathrm{cm}$ steel bar. C: The bottom view of the steel bar with groove shown in panel B. The infusion tube was inserted in the groove. I.D. = inner diameter; O.D. = outer diameter. Figure is available in color online only.

using a small dental drill. Infusions were performed at a depth of $5.5 \mathrm{~mm}$ from the brain surface along the steel bar of the UFD system (Fig. 2B). The following ascending infusion rates were applied to achieve a total infusion volume of $10 \mu \mathrm{l}$ with ultrasound: $0.2 \mu \mathrm{l} / \mathrm{min}$ for 20 minutes, followed by $0.5 \mu \mathrm{l} / \mathrm{min}$ for 12 minutes.

In the nonhuman primate study, the animal was initially anesthetized by intramuscular injection of pentobarbital sodium and atropine sulfate. Under deep ketamine and xylazine anesthesia, the primate was placed in a stereotactic frame. During the surgery and infusion, anesthesia was maintained by intramuscular administration of ketamine and xylazine (4:1). A sagittal incision was made to expose the cranium, followed by a bur hole in the skull positioned $10 \mathrm{~mm}$ anterior or $5 \mathrm{~mm}$ posterior and $10 \mathrm{~mm}$ bilateral from the point at the intersection of the midline with the line connecting the external auditory foramen fixed ear bar. Four bur holes were bored using a small dental drill. Infusions were performed at a depth of $12 \mathrm{~mm}$ from the brain surface along the steel bar of the UFD system. The following ascending infusion rates were applied to achieve a total infusion volume of $300 \mu \mathrm{l}$ with ultrasound: $0.2 \mu \mathrm{l} /$

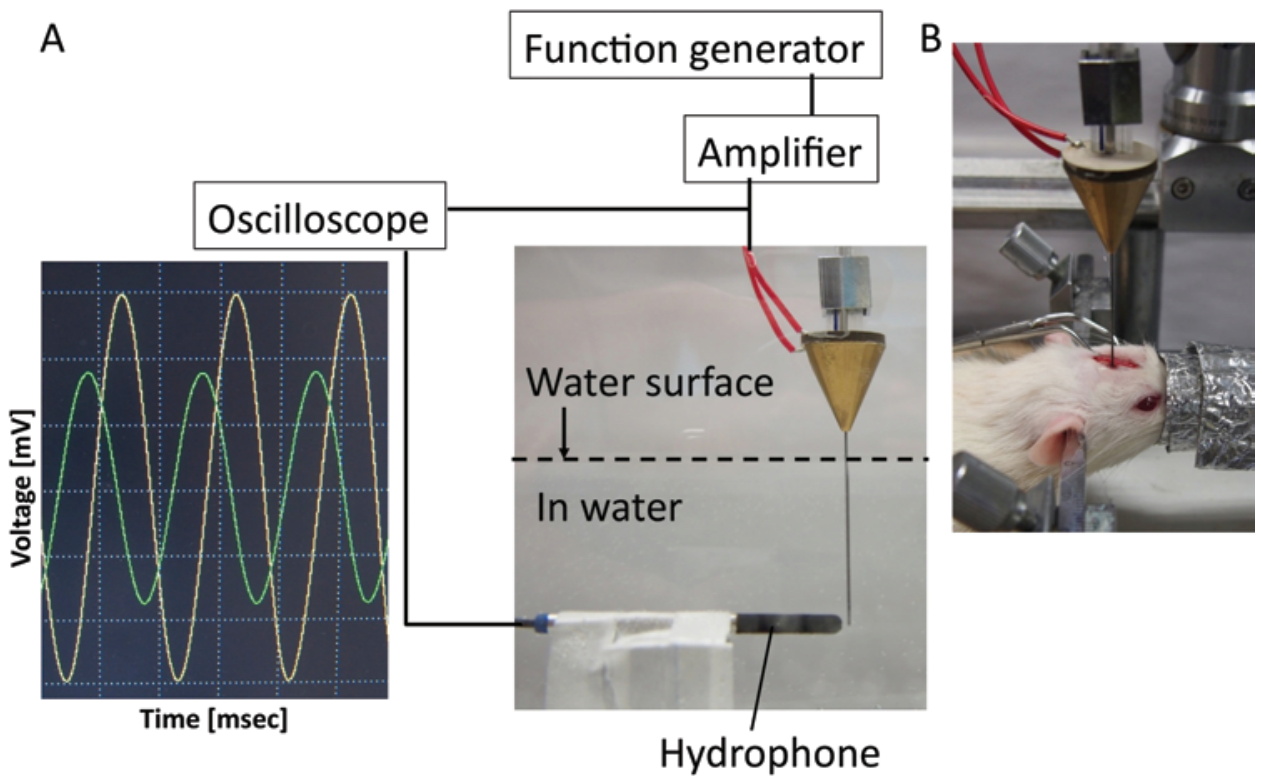

FIG. 2. A: A frame format ultrasound pressure measurement setup. Continuous waves at each frequency were generated using a function generator. The wave was magnified with the amplifier. This magnified wave was measured using an oscilloscope (yellow wave on the oscilloscope) and was applied to a piezoelectric transducer. The ultrasound pressure generated using the UFD system was measured using a hydrophone (green wave on the oscilloscope). B: In vivo study performed using a rat. 
$\min , 0.5 \mu \mathrm{l} / \mathrm{min}, 0.8 \mu \mathrm{l} / \mathrm{min}, 1.0 \mu \mathrm{l} / \mathrm{min}, 1.5 \mu \mathrm{l} / \mathrm{min}$, and 2.0 $\mu \mathrm{l} / \mathrm{min}$ for 10 minutes each, and $3.0 \mu \mathrm{l} / \mathrm{min}$ for 80 minutes.

In both rat and nonhuman primate studies, ultrasound was applied continuously as a sine wave, and at fixed frequency and fixed voltage, during a single infusion session. The application of ultrasound started with the infusion and stopped at the end of the infusion. Experiments using the UFD system were divided into 3 parts: 1) $2 \% \mathrm{Ev}$ ans blue dye (EBD) was infused into the rat brains. After the infusion, the Vd of EBD was evaluated histologically by making serial sections. 2) A mixture of 2\% EBD and gadopentetate dimeglumine (Gd-DTPA) (Magnevist, Bayer) was infused into rat brains. The Vd of Gd-DTPA was evaluated using MR images and that of EBD by making serial sections. The Vd of Gd-DTPA and that of EBD were compared. 3) Gd-DTPA was infused into the nonhuman primate brain. The Vd determined using MR images was compared with the Vd on MR images obtained by conventional CED, which we previously reported. ${ }^{26}$

\section{Evaluation of the Vd After UFD}

Healthy male Fischer 344 rats weighing approximately 200-250 g (Kumagai-shigeyasu Co., Ltd.) were randomly assigned to the following 6 groups by frequencies and applied voltages: Group a, control infused without application of ultrasound, but using the UFD device; Group b, ultrasound applied at $252 \mathrm{kHz}$ and $30 \mathrm{~V}$; Group c, applied at $252 \mathrm{kHz}$ and $60 \mathrm{~V}$; Group d, applied at $524 \mathrm{kHz}$ and 13 V; Group e, applied at $524 \mathrm{kHz}$ and $30 \mathrm{~V}$; and Group f, applied at $524 \mathrm{kHz}$ and $60 \mathrm{~V}$. Six rats were assigned to each group (36 rats total) and received a single 10- $\mu$ l UFD infusion of $2 \% \mathrm{EBD}$. To examine the difference of $\mathrm{Vd}$ under different frequencies, Groups c and d were set to almost equal acoustic pressure $(3 \mathrm{kPa})$. All rats were killed immediately after infusion. Brains were harvested, freshly frozen, and cut into serial $10-\mu \mathrm{m}$ coronal sections using a Tissue-Tek Cryo3 (Sakura Finetek USA, Inc.). Images of the sections were acquired using a BIOREVO BZ9000 microscope (Keyence). The volume of EBD distribution was calculated using ImageJ software (http://rsb.info. nih.gov/ij/download.html, National Institutes of Health). The EBD-stained regions were determined manually and their areas were calculated. Three independent examiners (Y.M., R.S., and R.Z.) performed this calculation. The average of these calculated areas was determined as the volume of EBD distribution.

For the Gd-DTPA/EBD infusion study, healthy male Fischer 344 rats weighing approximately $200-250 \mathrm{~g}$ were assigned to the following 2 groups: control infused without applying ultrasound but using the UFD system; and ultrasound applied at $260 \mathrm{kHz}$ and $60 \mathrm{~V}$. Six rats were assigned to each group (12 rats total) and received a single 10- $\mu$ l UFD infusion of $5 \mathrm{mM}$ Gd-DTPA with $2 \%$ EBD (Gd-DTPA/EBD). The MR images were acquired 1 hour after the infusion by using a 7-T Bruker PharmaScan system (Bruker Biospin) with a 38-mm-diameter birdcage coil. Each rat was initially anesthetized with $4 \%$ isoflurane and an air/oxygen mixture (7:3). The isoflurane level was lowered to $2.0 \% \pm 0.5 \%$ during the MRI scans. Throughout the MRI session, the animal's body temperature was kept at $36^{\circ} \mathrm{C} \pm 1^{\circ} \mathrm{C}$ with a feedback-controlled warm air system (SA Instruments). The respiration and rectal temperature were continuously monitored with a small-animal monitoring system.

To address the relationship between the distribution volume of EBD and Gd at the infusion site, the MR image-based distribution volumes were calculated with OsiriX software (OsiriX Foundation) using thresholdbased segmentation to grow 3D regions of interest with human-entered seed points. The lower threshold was increased from $10 \%, 20 \%$, and $30 \%$, to $40 \%$ of the maximum on the contralateral side. The "Grow Region (2D/3D segmentation)" tool made it possible to outline the Gd distribution automatically. For histological evaluation of the EBD distribution, the rats were killed immediately after each MRI session. The brains were harvested, freshly frozen using ice-cold isopentane, and cut into serial 10- $\mu \mathrm{m}$ coronal sections using a Tissue-Tek Cryo3. Images of sections were acquired using a BIOREVO BZ9000 microscope. The volume of EBD distribution was evaluated by the same procedure as described above. The volume of EBD distribution was compared with the volume of $\mathrm{Gd}$ distribution as detected by 7-T MRI.

The infusion study for the nonhuman primate was as follows. The surgical procedure was as described above. Infusion of $1 \mathrm{mM}$ Gd-DTPA/EBD was performed in both hemispheres of the nonhuman primate. Each hemisphere received $1 \mathrm{mM}$ Gd-DTPA/EBD at 2 sites (total 4 sites): the anterior and posterior parts of the corona radiata. All infusions were performed using the UFD system, and ultrasound was applied at $263 \mathrm{kHz} / 60 \mathrm{~V}$. During the MRI, the animal was sedated using ketamine and xylazine. The MR images were acquired immediately after the infusion. The volumes of Gd-DTPA were calculated using OsiriX, with the same procedure as described above.

\section{Acquisition of MRI Data}

The MRI data in the rats were acquired using a 7-T Bruker PharmaScan system with a 38-mm-diameter birdcage coil. The T1-weighted images were obtained using the 2D-RARE (rapid acquisition with relaxation enhancement) sequence with the following parameters: TR 1452 msec, TE $_{\text {eff }} 9$ msec, RARE factor 4 , FOV $32 \times 32 \mathrm{~mm}^{2}$, matrix size $256 \times 256$, voxel size $125 \times 125 \mu^{2}$, number of slices 30 , slice thickness $0.5 \mathrm{~mm}$, slice gap $0 \mathrm{~mm}$, and number of averages 8 . The total MR scanning time for each rat was approximately 10 minutes.

The MRI data in the nonhuman primate were acquired using a 0.5-T Toshiba Opart scanner (Toshiba Co.). The T1-weighted images were obtained using a spin-echo sequence with the following parameters: TR $24 \mathrm{msec}$, TE $10 \mathrm{msec}$, flip angle $30^{\circ}$, matrix size $144 \times 192$, number of excitations 6 , and slice thickness $0 \mathrm{~mm}$. The total scanning time for the nonhuman primate was approximately 22 minutes.

\section{Histological Examination Immediately After UFD}

For histological examination immediately after UFD, 6 healthy male Fischer 344 rats weighing approximately 200-250 g were assigned to the following 2 groups (3 rats in each group): a control group infused with $10 \mu \mathrm{l}$ 

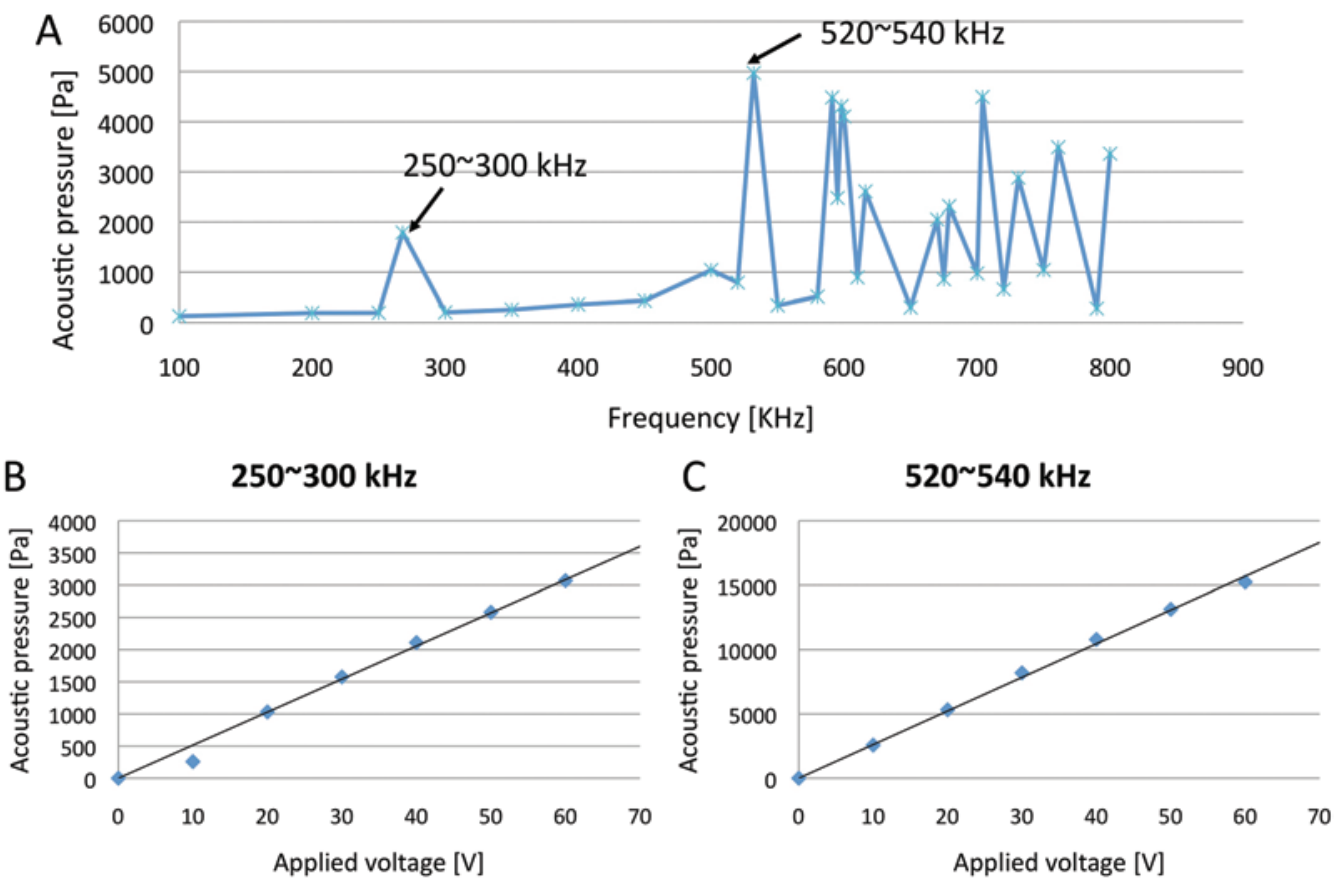

FIG. 3. Charts showing frequency characteristics and results of applied voltage. A: Frequency characteristics. The acoustic pressure at a resonance frequency increases at the same applied voltage. Bands of resonance frequencies were mainly recorded at $250-300 \mathrm{kHz}$ and $520-540 \mathrm{kHz}$. B and C: In these bands of resonance frequencies, output acoustic pressure was proportional to applied voltage. Figure is available in color online only.

of $2 \%$ EBD without applying ultrasound but using the UFD system; and a UFD group infused with $10 \mu \mathrm{l}$ of $2 \%$ EBD applied at $260 \mathrm{kHz} / 60 \mathrm{~V}$. All rats were killed immediately after infusion. Their brains were harvested and cut into serial $50-\mu \mathrm{m}$ coronal sections using a vibratome LinearSlicer PRO 10 (Dosaka EM Co., Ltd.). Immediately after sectioning, images were acquired using a BIOREVO BZ9000 microscope.

\section{Evaluation of Tissue Injury}

Healthy male Fischer 344 rats weighing 200-250 g received a single 10- $\mu$ l UFD infusion of normal saline with application at $260 \mathrm{kHz} / 60 \mathrm{~V}$. Three rats were assigned, and all were killed 1 week after infusion. Their brains were harvested after transcardial perfusion with normal saline, and fixed with cold $4 \%$ paraformaldehyde overnight in a refrigerator. Brains were subjected to paraffin sectioning $(4 \mu \mathrm{m})$ and histological examination using $\mathrm{H} \& \mathrm{E}$ and NeuN staining. For NeuN staining, sections were deparaffinized and then heated in $10 \mathrm{mM}$ citric acid at $\mathrm{pH} 6.0$ in a microwave oven for 15 minutes. These sections were then rinsed in phosphate-buffered saline (PBS), and mouse NeuN monoclonal antibody (Chemicon) diluted 1:1000 in PBS was applied. Sections were incubated overnight at $4^{\circ} \mathrm{C}$. The sections were then immersed in $0.3 \% \mathrm{H}_{2} \mathrm{O}_{2}$ diluted in methanol (Wako Chemicals) for 20 minutes at room temperature, and rinsed 3 times in PBS. The N-Histofine Simple Stain MAX PO (Nichirei) was then applied for 20 minutes at room temperature. After 3 rinses in PBS, the sections were exposed to $0.05 \%$ 3,3-diaminobenzidine tetrahydrochloride (Sigma) and $0.01 \% \mathrm{H}_{2} \mathrm{O}_{2}$ in $0.1 \mathrm{M}$ PBS ( $\mathrm{pH}$ 7.4) for 15-20 minutes to produce a brown reaction product. All steps were followed by appropriate washes in PBS. Slides were then counterstained with hematoxylin.

\section{Statistical Analyses}

Statistical analyses were performed using GraphPad Prism 5 for Windows (GraphPad Software, Inc.). All experiments were repeated 3 times and the differences for 2 sample comparisons were determined using the Student t-test. One-way ANOVA was used for multiple comparisons. Significance was set at $p<0.05$.

\section{Results \\ Optimal Frequencies}

The optimal resonance frequencies were determined by measuring the output acoustic pressure (Fig. 3). In the bands of $250-300 \mathrm{kHz}$ and $520-540 \mathrm{kHz}$, resonance frequency was constantly observed (Fig. 3A). At frequencies higher than $600 \mathrm{kHz}$, resonance frequencies were sometimes observed but were unstable and not reproducible; therefore, they were not used for the in vivo study. The acoustic pressure was increased proportionally by changing the applied voltage at each resonance frequency (Fig. $3 \mathrm{~B}$ and $\mathrm{C})$.

\section{Volume of Distribution of EBD Using the UFD System}

The tissue distributions of 2\% EBD after its infusion into the rat brain using the UFD system were as follows (values are expressed as the mean $\pm \mathrm{SD}$ ): Group a, control group of rats infused without ultrasound: $25.4 \pm 3.52 \mathrm{~mm}^{3}$; Group b, rats subjected to $252 \mathrm{kHz} / 30 \mathrm{~V}: 37.17 \pm 7.05$ 

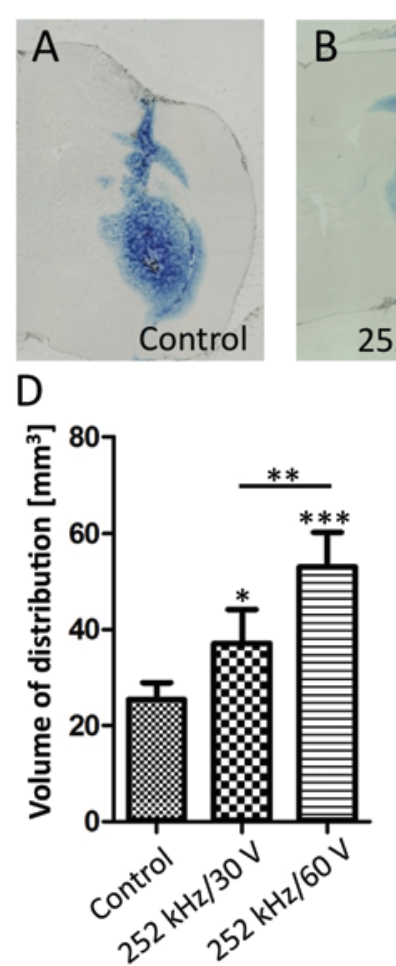
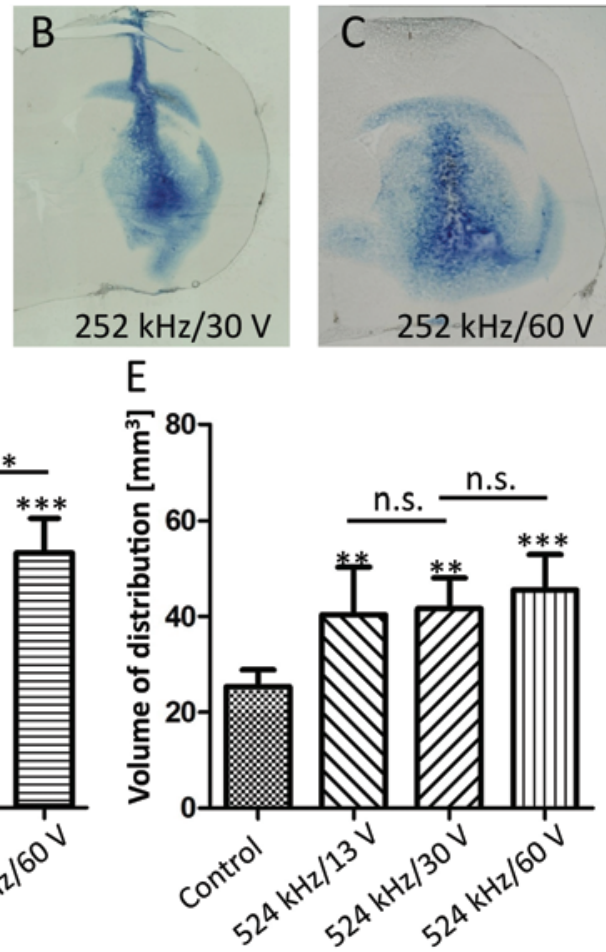
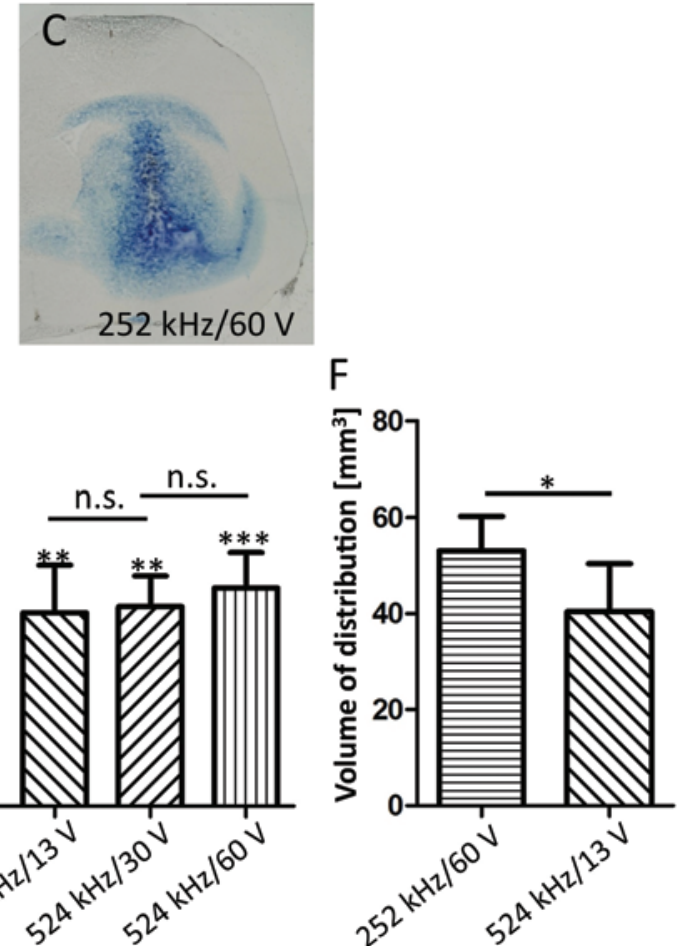

FIG. 4. A-C: Unstained sections of brain showing distribution of injected $2 \%$ EBD. Original magnification $\times 20$. A: Control. Infusion was performed using the UFD system, but without ultrasound application. B and C: Infusion was performed using the UFD system with application of resonance ultrasound. Applied ultrasound and voltage levels were $252 \mathrm{kHz}$ and $30 \mathrm{~V}(\mathrm{~B})$ and $252 \mathrm{kHz}$ and $60 \mathrm{~V}(\mathrm{C})$. The UFD system with ultrasound application enlarged the distribution of EBD. D-F: Bar graphs showing the Vd of $10 \mu \mathrm{l}$ of $2 \%$ EBD using the UFD system. When the applied resonance frequency was $252 \mathrm{kHz}$, the Vd increased significantly with an increase of applied voltage (D). When the applied resonance frequency was $524 \mathrm{kHz}$, the Vds differed significantly between the control and ultrasound-applied groups, but did not differ significantly among the applied voltages of 13, 30, and $60 \mathrm{~V}$ (E). Panels D and $\mathrm{E}$ were compared using Tukey's multiple comparison test in 1-way ANOVA. The output acoustic pressures were nearly equal (approximately $3 \mathrm{kPa}$ ) when $252 \mathrm{kHz} / 60 \mathrm{~V}$ or $524 \mathrm{kHz} / 13 \mathrm{~V}$ was applied $(\mathrm{F})$. The $\mathrm{Vd}$ of the group in which $252 \mathrm{kHz} / 60 \mathrm{~V}$ was applied was significantly larger than that in which $524 \mathrm{kHz} / 13 \mathrm{~V}$ was applied. Unpaired Student t-test: * $0.01 \leq p<0.05 ;{ }^{* *}, 0.001 \leq p$ $<0.01$; and ${ }^{* * *}, p<0.001$. n.s. $=$ not significant. Figure is available in color online only.

$\mathrm{mm}^{3}$; Group c, $252 \mathrm{kHz} / 60 \mathrm{~V}: 53.03 \pm 7.25 \mathrm{~mm}^{3}$; Group d, $524 \mathrm{kHz} / 13 \mathrm{~V}: 40.42 \pm 9.96 \mathrm{~mm}^{3}$; Group e, $524 \mathrm{kHz} / 30$ $\mathrm{V}: 41.67 \pm 6.45 \mathrm{~mm}^{3}$; and Group f, $524 \mathrm{kHz} / 60 \mathrm{~V}: 45.58 \pm$ $7.38 \mathrm{~mm}^{3}$. The Vds of the UFD groups (Groups b-f) were significantly larger than that of the control group (Group a). Between the groups in which $252 \mathrm{kHz}$ was applied, the Vd of Group c, which was subjected to $252 \mathrm{kHz} / 60 \mathrm{~V}$, was significantly larger than that of Group $b$, which was subjected to $252 \mathrm{kHz} / 30 \mathrm{~V}$ ( $\mathrm{p}<0.01$, 1-way ANOVA) (Fig. $4 \mathrm{~A}-\mathrm{D})$. However, among the groups in which $524 \mathrm{kHz}$ was applied (Groups d-f), the differences in Vd were not significant (1-way ANOVA) (Fig. 4E).

To examine the effect of frequency on Vd, groups subjected to $252 \mathrm{kHz} / 60 \mathrm{~V}$ and $524 \mathrm{kHz} / 13 \mathrm{~V}$ were compared. The acoustic pressure was nearly equal between these 2 groups. Consequently, the $\mathrm{Vd}$ of the group in which 252 $\mathrm{kHz} / 60 \mathrm{~V}$ was applied was significantly larger than that of the group in which $524 \mathrm{kHz} / 13 \mathrm{~V}$ was applied $(\mathrm{p}<0.05$, Student t-test) (Fig. 4F).

\section{Comparison Between the Distributions of Gd-DTPA and EBD}

After the infusion of Gd-DTPA into intact rodent brain using the UFD system, the distribution of the infusate was detected by MRI. The Vd of Gd-DTPA after infusion with ultrasound was larger than that of the control group (Fig. $5 \mathrm{G})$. The shapes of distribution of Gd-DTPA and EBD were nearly identical (Fig. 5A-F).

\section{Histological Evaluation Immediately After UFD}

Histological examination performed immediately after UFD revealed more homogeneous distribution of the EBD in the group in which ultrasound was applied compared with the control group. In the control group, staining of the linear structures, which were likely to be vessels and fibers (Fig. 6A and B; arrowheads), was often found with rather heterogeneous distribution. When ultrasound was applied, distributions of the EBD were more homogeneous, without staining of the linear structures (Fig. 6C and D).

\section{Evaluation of Tissue Injury in Rat Brain}

To evaluate the tissue injury associated with UFD, 6 healthy male Fischer 344 rats ( 3 in each group) received a single 10- $\mu$ l UFD infusion of normal saline without or with $260 \mathrm{kHz} / 60 \mathrm{~V}$ ultrasound. Rats were killed 1 week after infusion. All infused rats were healthy and no deficits 

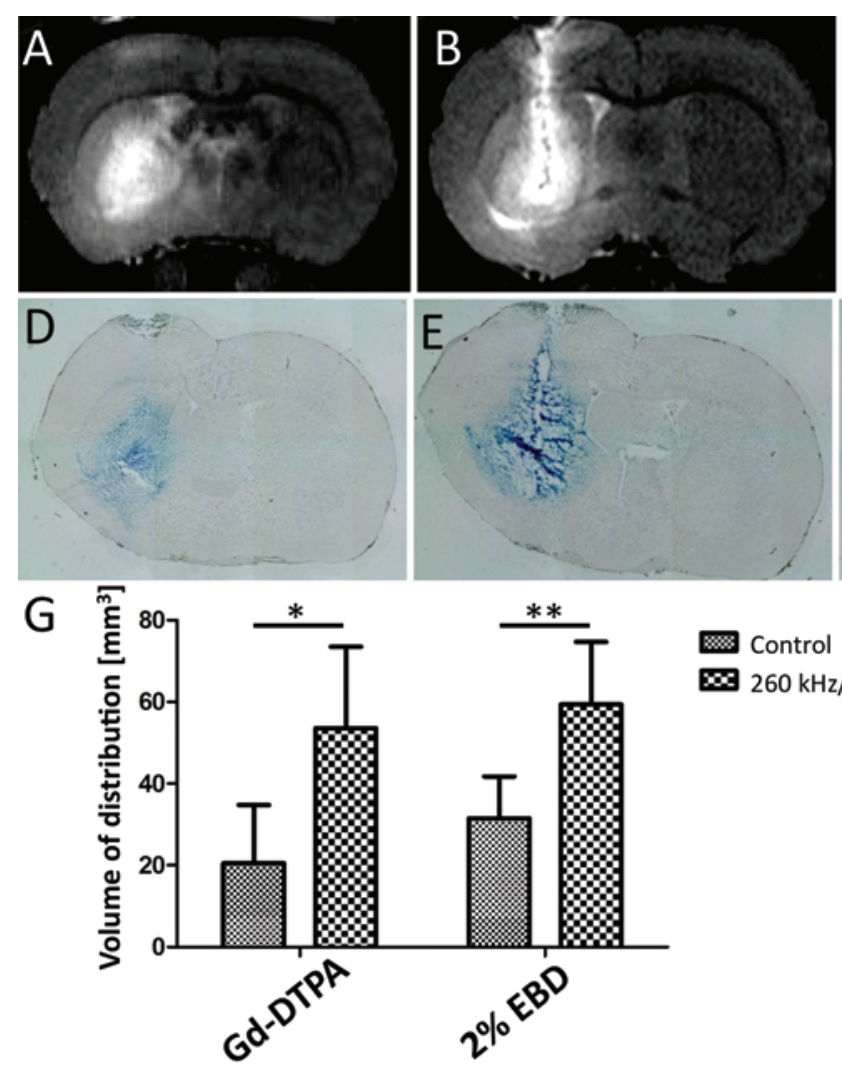

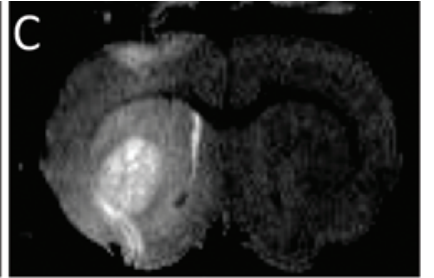

$\mathrm{F}$

Control

$\infty 260 \mathrm{kHz} / 60 \mathrm{~V}$

FIG. 5. The Vd of $5 \mathrm{mM}$ Gd-DTPA on 7-T MR images. A-C: Sections of brain injected using the UFD system with ultrasound: 260 $\mathrm{kHz} / 60 \mathrm{~V}$. D-F: The histological unstained sections corresponding to A, B, and C, respectively. Original magnification $\times 20$. G: Bar graph showing comparison of the Vds. When the signal intensity threshold was set to a level of a $40 \%$ increase compared with that in the contralateral hemisphere, the Vd of Gd-DTPA in the control group was calculated as $17.1 \pm 15.2 \mathrm{~mm}^{3}$ (mean \pm SD). The $\mathrm{Vd}$ of Gd-DTPA in the group in which $260 \mathrm{kHz} / 60 \mathrm{~V}$ was applied was calculated as $53.5 \pm 19.6 \mathrm{~mm}^{3}$. The Vds of coinfused $2 \%$ EBD judged from histological sections were $29.7 \pm 10.2 \mathrm{~mm}^{3}$ in the control group and $59.4 \pm 15.4 \mathrm{~mm}^{3}$ in the ultrasound-applied group. Unpaired Student t-test: *, $0.01 \leq p<0.05$ and ${ }^{* *}, 0.001 \leq p<0.01$. Figure is available in color online only.

were found until use. Histological examination revealed limited tissue damage along the steel bar tract; however, brain tissue damage due to ultrasound was almost negligible (Fig. 7).

\section{Volume of Gd-DTPA With Use of the UFD System in the Nonhuman Primate}

The Vd of Gd-DTPA in the nonhuman primate using the UFD system with application at $263 \mathrm{kHz} / 60 \mathrm{~V}$ was $1209.8 \pm 193.6 \mathrm{~mm}^{3}$ (mean $\pm \mathrm{SD}$ ). We previously reported that the Vd of Gd-DTPA attained in 7 nonhuman primates by using the conventional CED method was $568.6 \pm 141.0$ $\mathrm{mm}^{3}{ }^{26}$ The $\mathrm{Vd}$ of Gd-DTPA attained in the nonhuman primate by using the UFD system was thus significantly larger than that attained using the conventional CED method (Fig. 8).

\section{Discussion}

\section{Efficacy of the UFD System}

The newly developed UFD system effectively enlarged the $\mathrm{Vd}$ to more than that attained using the conventional CED method. In the rat study, the Vd of $2 \%$ EBD that was attained using the UFD method was significantly larger than that of the control group. Compared with that of the control group ( $\mathrm{Vd}, 25.4 \pm 3.52 \mathrm{~mm}^{3}$ ), the $\mathrm{Vd}$ of the 252 $\mathrm{kHz} / 60 \mathrm{~V}$ applied group was almost twice as large (Fig. 4). Among the groups that received $252 \mathrm{kHz}, \mathrm{Vd}$ showed a tendency to enlarge depending on the input voltage (Fig. 4D). However, in the groups that received $524 \mathrm{kHz}$, the enlargement of the Vd did not differ significantly among applied voltages of 13, 30, and $60 \mathrm{~V}$ (Fig. 4E). These results suggest that a low resonance frequency is more effective than a high resonance frequency, and that a high input voltage tends to enlarge the $\mathrm{Vd}$ at the same frequency.

Real-time monitoring of drug distribution was also possible with CED. ${ }^{21}$ In the Gd-DTPA/EBD coinfusion study, the Vd of Gd-DTPA and coinfused EBD almost overlapped (Fig. 5A-F). In this study, the signal intensity threshold was set to the level of a $40 \%$ increase compared with the contralateral hemisphere. When the signal intensity threshold was set to more than a $10 \%, 20 \%, 30 \%$, or $40 \%$ increase compared with the contralateral hemisphere, the Vds of Gd-DTPA in the control group, in which ultrasound was not applied but a UFD device was used, were calculated as $59.5 \pm 27.3 \mathrm{~mm}^{3}, 38.4 \pm 20.7 \mathrm{~mm}^{3}, 24.8 \pm 16.9 \mathrm{~mm}^{3}$, and $17.1 \pm 15.2 \mathrm{~mm}^{3}$, respectively. Similarly, the Vds of Gd-DTPA in the UFD group, in which $260 \mathrm{kHz} / 60 \mathrm{~V}$ was 


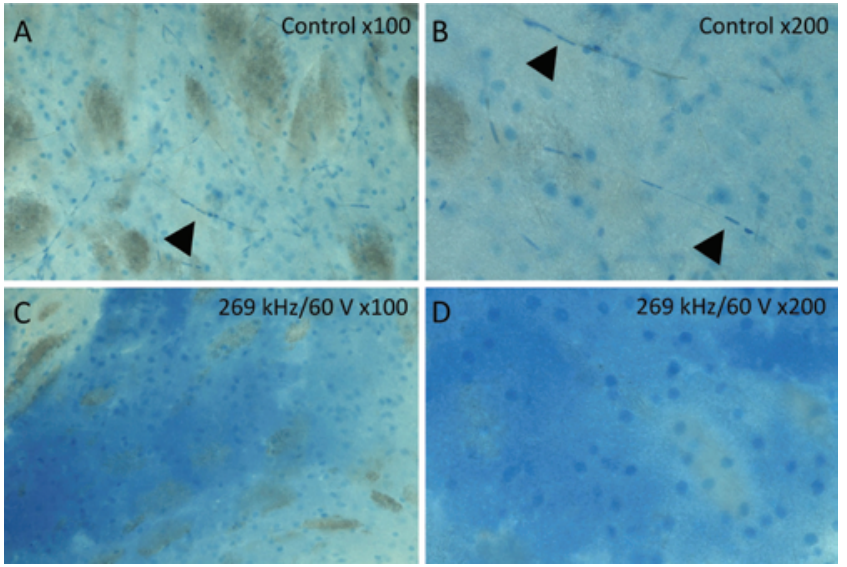

FIG. 6. Photomicrographs of sections obtained immediately after UFD, which were used for histological examination. A and B: Control group, $10 \mu \mathrm{l}$ of $2 \%$ EBD infused using the UFD system but without ultrasound application. In panels A and B, 2\% EBD is heterogeneously distributed into the brain parenchyma. Many linear structures (arrowheads), which are probably perivascular space or perifiber space, are stained, indicating that the infused dye traversed along the lower-pressure area. $\mathbf{C}$ and D: Ultrasound-applied group, $10 \mu$ of $2 \%$ EBD infused using the UFD system applied at $269 \mathrm{kHz} / 60 \mathrm{~V}$. In panels $\mathrm{C}$ and D, 2\% EBD is distributed more homogeneously than that observed in the control group. All sections were freshly cut and unstained. A and C: Original magnification $\times 100$. B and D: Original magnification $\times 200$.

applied, were calculated as $139.9 \pm 29.6 \mathrm{~mm}^{3}, 97.8 \pm 28.1$ $\mathrm{mm}^{3}, 70.3 \pm 25.1 \mathrm{~mm}^{3}$, and $53.5 \pm 19.6 \mathrm{~mm}^{3}$ at $10 \%, 20 \%$, $30 \%$, and $40 \%$, respectively. Because the Vds of coinfused $2 \%$ EBD judged from the histological examination were $29.7 \pm 10.2 \mathrm{~mm}^{3}$ in the control group and $59.4 \pm 15.4 \mathrm{~mm}^{3}$ in the group in which ultrasound was applied, the signal intensity threshold at which the Vds of Gd-DTPA and 2\% EBD become identical was defined as 40\% (Fig. 5G).

In the nonhuman primate study, the $\mathrm{Vd}$ of $1 \mathrm{mM} \mathrm{Gd}-$ DTPA attained using the UFD system was significantly larger than that of conventional CED (Fig. 8C). Whereas the Vd of $1 \mathrm{mM} \mathrm{Gd-DTPA}$ that was attained using the UFD system was $1209.8 \pm 193.6 \mathrm{~mm}^{3}$, that of the conventional CED method was $568.6 \pm 141.0 \mathrm{~mm}^{3}$. The methods of infusion, including the infused agent $(1 \mathrm{mM} \mathrm{Gd}-$ DTPA); rate of infusion $(0.2 \mu \mathrm{l} / \mathrm{min}, 0.5 \mu \mathrm{l} / \mathrm{min}, 0.8 \mu \mathrm{l} /$ $\mathrm{min}, 1.0 \mu \mathrm{l} / \mathrm{min}, 1.5 \mu \mathrm{l} / \mathrm{min}$, and $2.0 \mu \mathrm{l} / \mathrm{min}$ for 10 minutes each, and $3.0 \mu \mathrm{l} / \mathrm{min}$ for 80 minutes); and Vd evaluation method were the same between these 2 studies. Although it has been demonstrated that a $5-\mathrm{mM}$ concentration of Gd-DTPA most accurately estimates the Vd over a wide range of molecular sizes, ${ }^{1}$ we used $1 \mathrm{mM}$ Gd-DTPA in the nonhuman primate study to compare the data with our previous nonhuman primate study ${ }^{26}$ in which conventional CED methods were tested under the same settings, including infusion rate and volume of Gd-DTPA infusion. After the study, no neurological deterioration was observed and the nonhuman primate was healthy. Consequently, the UFD system that we developed safely enlarged the Vd in the rats as well as in the monkey.

\section{Optimal Frequencies and Acoustic Pressures}

The resonance frequencies of the fabricated UFD sys-
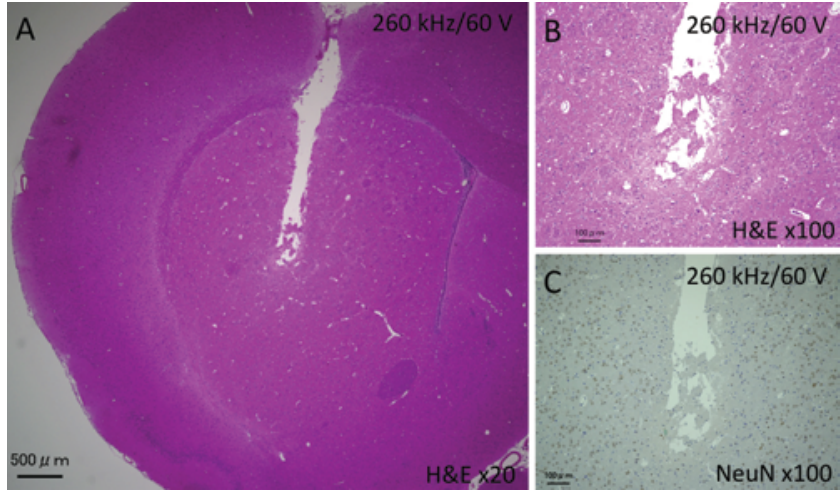

FIG. 7. Evaluation of tissue injury after UFD. Healthy male Fischer 344 rats received a single 10- $\mu$ I UFD infusion of normal saline with 260 $\mathrm{kHz} / 60 \mathrm{~V}$ ultrasound. Rats were killed 1 week after infusion. A: A representative image (low-power field) containing the insertion tract. $H$ \& $E$, original magnification $\times 20$. B: Image showing a high-power field at the tip of the infusion tract. $H \& E$, original magnification $\times 100$. C: Section prepared with NeuN stain, original magnification $\times 100$. Figure is available in color online only.

tem were in the bands of $250-300 \mathrm{kHz}$ and $520-540 \mathrm{kHz}$. The resonance frequencies were intended to transmit acoustic energy to the target with little energy loss. Frequency and acoustic pressure influenced the Vd. The Vd tended to increase in proportion to the acoustic pressure and in inverse proportion to the frequency (Fig. 4). These results were in line with a previous report..$^{16}$ The ultrasound frequencies previously used in in vivo studies were $750 \mathrm{kHz},{ }^{20} 1 \mathrm{MHz},{ }^{16}$ and $1.34 \mathrm{MHz} .{ }^{12,13}$ The acoustic pressures previously used in in vivo studies were 150 $250 \mathrm{kPa}^{20}$ and $1240 \mathrm{kPa} .^{16}$ Our UFD system did not exceed $5 \mathrm{kPa}$ in bands of $250-300 \mathrm{kHz}$ and $16 \mathrm{kPa}$ in bands of $520-540 \mathrm{kHz}$. The bands of $250-300 \mathrm{kHz}$, which effectively improved the $\mathrm{Vd}$, could be used with minimal tissue injuries (Fig. 7). The time-averaged intensity of the ultrasound was $0.006 \mathrm{~W} / \mathrm{cm}^{2}$ in bands of $250-300 \mathrm{kHz}$, lower than those used in a previous study $\left(0.0497 \mathrm{~W} / \mathrm{cm}^{2}\right) .{ }^{13}$ The optimal frequencies may be controversial and require further investigation because neither the previously reported time-reversal transcranial ultrasound technique nor the transbrain surface technique is similar to our system and may have different characteristics. ${ }^{12,13,16,20}$

\section{Mechanisms That Enlarged Vd Using the UFD System}

The mechanisms behind the enlargement of Vd using the UFD system are still unclear. The mechanism for FUS is believed to involve ultrasound nonthermal bioeffects, particularly the induction of acoustic cavitation and its disruptive interaction with the brain vasculature, increasing blood vessel permeability ${ }^{17}$ However, our UFD system acts beyond the blood-brain barrier because it involves the direct injection of agents to the target. Ultrasound may increase the $\mathrm{Vd}$ by augmenting convective forces during CED or by increasing the permeability of brain tissue. ${ }^{16}$ Low-intensity ultrasound widened intercellular spaces between epithelial cells at fluid-tissue interfaces. ${ }^{6}$ Hypothetically, the mechanisms of improved $\mathrm{Vd}$ attained using the UFD device may include sonophoresis and sonopora- 

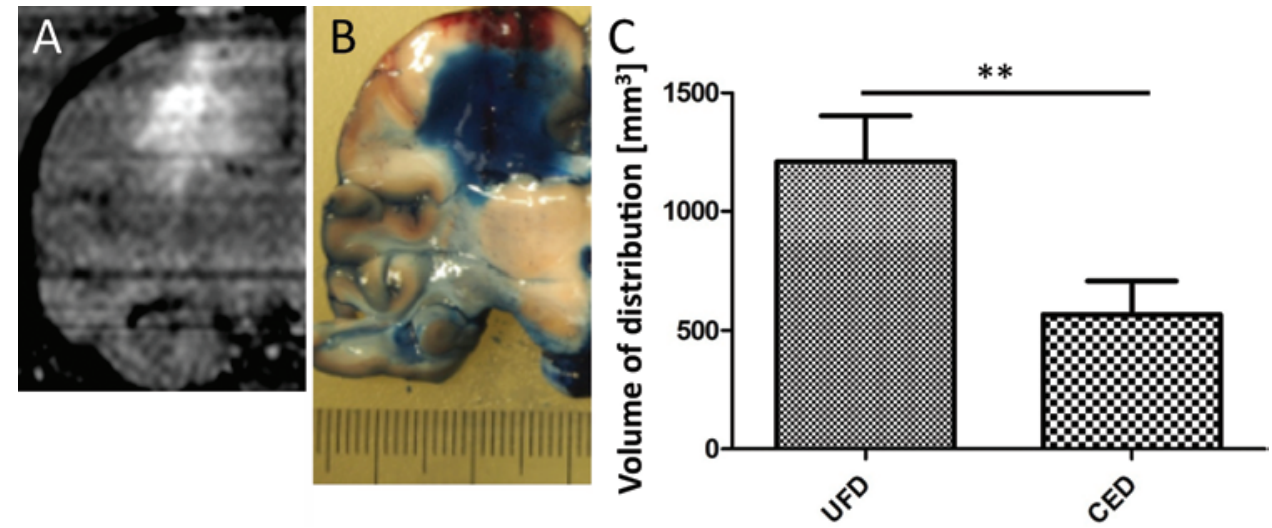

FIG. 8. Distribution of $1 \mathrm{mM}$ Gd-DTPA and $2 \%$ EBD in the brain of Macaca fascicularis. A: Tissue distribution of $1 \mathrm{mM}$ Gd-DTPA was successfully detected by MRI. B: Brain slice obtained at a site close to A. C: Bar graph. The volume of Gd-DTPA distribution in the nonhuman primate infused using the UFD system was $1209.8 \pm 193.6 \mathrm{~mm}^{3}$. This was significantly larger than that achieved with the conventional CED system. Unpaired Student t-test: ${ }^{* *}, 0.001 \leq p<0.01$. Figure is available in color online only.

tion. The term sonophoresis was often used for transdermal drug delivery. ${ }^{28}$ Sonophoresis can occur by acoustic cavitation (inertial cavitation), in which shock waves are generated after the collapse of cavitation bubbles. The shock waves might microscopically disrupt not only the tight junction but also the extracellular space. Therefore, the Vds that were attained using the UFD device got larger than those of the conventional CED method. The sonoporation effect may also facilitate enlargement of the Vds. The sonoporation enhances the uptake of low- and highweight molecules into cells and tissues. This effect may transiently compromise the integrity of cell membranes or tissues. ${ }^{18}$

Rapid absorption of injected molecules may make convective force pass through the tissue easily. Consequently, the UFD device may have achieved enlargement of the Vds compared with the conventional CED method. Our histo-

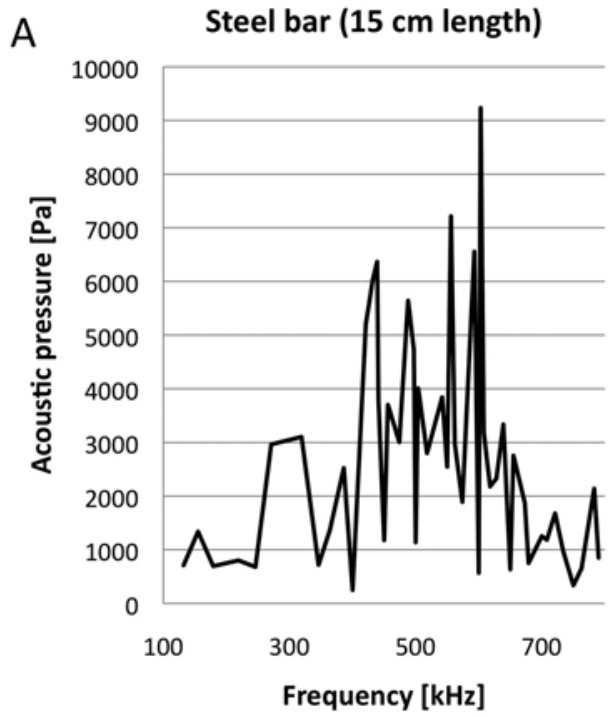

logical examination performed immediately after infusion using the UFD system suggested a more homogeneous distribution than conventional CED (Fig. 6). Staining of the linear structures, which probably consist of vessels or fibers, was observed in the control group, with rather heterogeneous distributions (Fig. 6A and B). It is known that infusates traverse perivascular or perifiber spaces in traditional CED because these are the sites of lower pressure. ${ }^{10}$ On the other hand, in the UFD group, EBD was distributed homogeneously and was less likely to have traversed perivascular or perifiber space (Fig. 6C and D). These findings suggested that applied ultrasound may have opened the extracellular space, which resulted in homogeneous distribution and enlarged Vd. When the UFD system was tested in the brain phantom gel, enlargement of the $\mathrm{Vd}$ of $2 \% \mathrm{EBD}$ was not observed (data not shown). This finding also suggests the contribution of widened extracellular space.

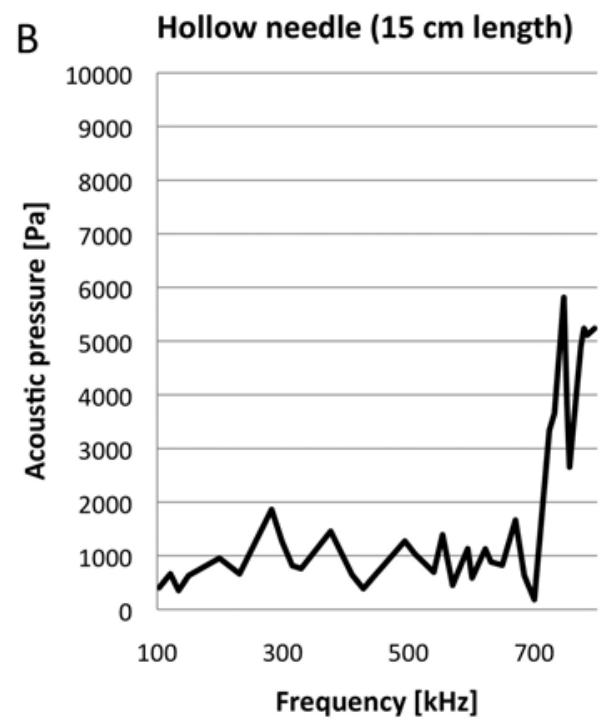

FIG. 9. Graphs showing frequency characteristics of steel bar and hollow needle of the same length $(15 \mathrm{~cm})$. High acoustic pressure was obtained using the steel bar. A: Frequency characteristics of the 15-cm steel bar. B: Frequency characteristics of the hollow needle. 


\section{Merits and Limitations of the UFD System}

The merits of this UFD system are as follows. The previously reported transbrain surface ultrasound-assisted CED device requires the removal of a bone flap to place PZT on the brain surface. ${ }^{13,16}$ However, our device does not require craniotomy; a single bur hole is sufficient to perform ultrasound assistance. In addition, transbrain surface ultrasound-assisted CED devices might not transmit ultrasound effectively to deep brain lesions because the long, hollow needle attenuates ultrasound. When the steel bar of our UFD device was changed to a hollow needle, the output acoustic pressure was attenuated. In the device used in this study, the horn and steel bar conduct ultrasound to the deeply targeted region without substantial attenuation (Fig. 9). The FUS-assisted drug delivery requires systemic drug administration, and data on the Vds for large brains have been limited., ${ }^{4,5,9,15}$ The CED method bypasses the blood-brain barrier, does not require systemic drug administration, and can deliver high concentrations of therapeutic agents directly against the targeted lesion. The transcranial time-reversal acoustics-assisted CED method requires the practitioner to attach the reverberator to another site on the cranium. In addition, the effectiveness of this method in delivering drugs to the deep target has not yet been demonstrated. ${ }^{12,20}$

The limitations of this study are as follows. The current system is not implantable, so the infusion needs to be completed within a reasonable time frame and may require multiple surgeries for multiple infusions. In addition, the current system is not MRI-compatible. Because MR monitoring is necessary to apply this method clinically, we are now developing an MRI-compatible system.

\section{Conclusions}

Use of the newly developed UFD system was a more effective strategy to enlarge the Vd than the conventional CED method. In addition, tissue injury due to the ultrasound was limited along the steel bar tract, and brain tissue damage was almost negligible. The UFD system is a novel delivery system that may provide a new strategy for CNS diseases.

\section{Acknowledgments}

This work was supported in part by A-step (\#241FT0498 to R.S.) from the Japan Science and Technology Agency, and by a Grant-in-Aid for Young Scientists (B) (\#21791341 to R.S.) from the Ministry of Education, Culture, Sports, Science, and Technology in Japan and from the Japan Society for the Promotion of Science.

\section{References}

1. Asthagiri AR, Walbridge S, Heiss JD, Lonser RR: Effect of concentration on the accuracy of convective imaging distribution of a gadolinium-based surrogate tracer. J Neurosurg 115:467-473, 2011

2. Bauknight WM, Chakrabarty S, Hwang BY, Malone HR, Joshi S, Bruce JN, et al: Convection enhanced drug delivery of BDNF through a microcannula in a rodent model to strengthen connectivity of a peripheral motor nerve bridge model to bypass spinal cord injury. J Clin Neurosci 19:563569,2012
3. Bobo RH, Laske DW, Akbasak A, Morrison PF, Dedrick RL, Oldfield EH: Convection-enhanced delivery of macromolecules in the brain. Proc Natl Acad Sci U S A 91:2076-2080, 1994

4. Burgess A, Hynynen K: Noninvasive and targeted drug delivery to the brain using focused ultrasound. ACS Chem Neurosci 4:519-526, 2013

5. Etame AB, Diaz RJ, Smith CA, Mainprize TG, Hynynen K, Rutka JT: Focused ultrasound disruption of the blood-brain barrier: a new frontier for therapeutic delivery in molecular neurooncology. Neurosurg Focus 32(1):E3, 2012

6. Frenkel V, Oberoi J, Stone MJ, Park M, Deng C, Wood BJ, et al: Pulsed high-intensity focused ultrasound enhances thrombolysis in an in vitro model. Radiology 239:86-93, 2006

7. Inoue T, Yamashita Y, Nishihara M, Sugiyama S, Sonoda Y, Kumabe T, et al: Therapeutic efficacy of a polymeric micellar doxorubicin infused by convection-enhanced delivery against intracranial 9L brain tumor models. Neuro Oncol 11:151-157, 2009

8. Kikuchi T, Saito R, Sugiyama S, Yamashita Y, Kumabe T, Krauze M, et al: Convection-enhanced delivery of polyethylene glycol-coated liposomal doxorubicin: characterization and efficacy in rat intracranial glioma models. J Neurosurg 109:867-873, 2008

9. Kinoshita M, McDannold N, Jolesz FA, Hynynen K: Noninvasive localized delivery of Herceptin to the mouse brain by MRI-guided focused ultrasound-induced blood-brain barrier disruption. Proc Natl Acad Sci U S A 103:11719-11723, 2006

10. Krauze MT, Saito R, Noble C, Bringas J, Forsayeth J, McKnight TR, et al: Effects of the perivascular space on convection-enhanced delivery of liposomes in primate putamen. Exp Neurol 196:104-111, 2005

11. Kunwar S, Chang S, Westphal M, Vogelbaum M, Sampson J, Barnett G, et al: Phase III randomized trial of CED of IL13-PE38QQR vs Gliadel wafers for recurrent glioblastoma. Neuro Oncol 12:871-881, 2010

12. Lewis GK Jr, Guarino S, Gandhi G, Filinger L, Lewis GK Sr, Olbricht WL, et al: Time-reversal Techniques in Ultrasoundassisted Convection-enhanced Drug Delivery to the Brain: Technology Development and In Vivo Evaluation. Proc Meet Acoust 11:20005-20031, 2011

13. Lewis GK Jr, Schulz ZR, Pannullo SC, Southard TL, Olbricht WL: Ultrasound-assisted convection-enhanced delivery to the brain in vivo with a novel transducer cannula assembly: laboratory investigation. J Neurosurg 117:1128-1140, 2012

14. LeWitt PA, Rezai AR, Leehey MA, Ojemann SG, Flaherty AW, Eskandar EN, et al: AAV2-GAD gene therapy for advanced Parkinson's disease: a double-blind, sham-surgery controlled, randomised trial. Lancet Neurol 10:309-319, 2011

15. Liu HL, Yang HW, Hua MY, Wei KC: Enhanced therapeutic agent delivery through magnetic resonance imaging-monitored focused ultrasound blood-brain barrier disruption for brain tumor treatment: an overview of the current preclinical status. Neurosurg Focus 32(1):E4, 2012

16. Liu Y, Paliwal S, Bankiewicz KS, Bringas JR, Heart G, Mitragotri S, et al: Ultrasound-enhanced drug transport and distribution in the brain. AAPS PharmSciTech 11:1005-1017, 2010

17. McDannold N, Vykhodtseva N, Hynynen K: Targeted disruption of the blood-brain barrier with focused ultrasound: association with cavitation activity. Phys Med Biol 51:793-807, 2006

18. Mitragotri S: Healing sound: the use of ultrasound in drug delivery and other therapeutic applications. Nat Rev Drug Discov 4:255-260, 2005

19. Nakamura T, Saito R, Sugiyama S, Sonoda Y, Kumabe T, Tominaga T: Local convection-enhanced delivery of chemo- 
therapeutic agent transiently opens blood-brain barrier and improves efficacy of systemic chemotherapy in intracranial xenograft tumor model. Cancer Lett 310:77-83, 2011

20. Olbricht W, Sistla M, Ghandi G, Lewis G Jr, Sarvazyan A: Time-reversal acoustics and ultrasound-assisted convectionenhanced drug delivery to the brain. J Acoust Soc Am 134:1569-1575, 2013

21. Saito R, Bringas JR, Panner A, Tamas M, Pieper RO, Berger MS, et al: Convection-enhanced delivery of tumor necrosis factor-related apoptosis-inducing ligand with systemic administration of temozolomide prolongs survival in an intracranial glioblastoma xenograft model. Cancer Res 64:6858-6862, 2004

22. Saito R, Krauze MT, Bringas JR, Noble C, McKnight TR, Jackson P, et al: Gadolinium-loaded liposomes allow for realtime magnetic resonance imaging of convection-enhanced delivery in the primate brain. Exp Neurol 196:381-389, 2005

23. Saito R, Krauze MT, Noble CO, Drummond DC, Kirpotin DB, Berger MS, et al: Convection-enhanced delivery of LsTPT enables an effective, continuous, low-dose chemotherapy against malignant glioma xenograft model. Neuro Oncol 8:205-214, 2006

24. Sampson JH, Archer G, Pedain C, Wembacher-Schröder E, Westphal M, Kunwar S, et al: Poor drug distribution as a possible explanation for the results of the PRECISE trial. J Neurosurg 113:301-309, 2010

25. Stiles DK, Zhang Z, Ge P, Nelson B, Grondin R, Ai Y, et al: Widespread suppression of huntingtin with convection-enhanced delivery of siRNA. Exp Neurol 233:463-471, 2012

26. Sugiyama S, Saito R, Nakamura T, Yamashita Y, Yokosawa M, Sonoda Y, et al: Safety and feasibility of convectionenhanced delivery of nimustine hydrochloride co-infused with free gadolinium for real-time monitoring in the primate brain. Neurol Res 34:581-587, 2012
27. Sugiyama S, Yamashita Y, Kikuchi T, Saito R, Kumabe T, Tominaga T: Safety and efficacy of convection-enhanced delivery of ACNU, a hydrophilic nitrosourea, in intracranial brain tumor models. J Neurooncol 82:41-47, 2007

28. Tezel A, Mitragotri S: Interactions of inertial cavitation bubbles with stratum corneum lipid bilayers during lowfrequency sonophoresis. Biophys J 85:3502-3512, 2003

29. Yokosawa M, Sonoda Y, Sugiyama S, Saito R, Yamashita Y, Nishihara M, et al: Convection-enhanced delivery of a synthetic retinoid Am80, loaded into polymeric micelles, prolongs the survival of rats bearing intracranial glioblastoma xenografts. Tohoku J Exp Med 221:257-264, 2010

\section{Disclosure}

The authors report no conflict of interest concerning the materials or methods used in this study or the findings specified in this paper.

\section{Author Contributions}

Conception and design: Saito, Haga, Sonoda. Acquisition of data: Saito, Mano, Matsunaga, Zhang, Chonan, Haryu, Shoji, Sato, Sumiyoshi, Nonaka. Analysis and interpretation of data: Saito, Haga, Matsunaga. Drafting the article: Saito, Mano, Matsunaga, Sumiyoshi. Critically revising the article: Haga, Sonoda, Tsuruoka, Nishiyachi, Kawashima. Reviewed submitted version of manuscript: Haga, Kawashima. Statistical analysis: Saito, Chonan. Administrative/technical/material support: Tsuruoka, Nishiyachi. Study supervision: Saito, Tominaga.

\section{Correspondence}

Ryuta Saito, Department of Neurosurgery, Tohoku University Graduate School of Medicine, 1-1 Seiryo-machi, Aoba-ku, Sendai, Miyagi 980-8574, Japan. email: ryuta@nsg.med.tohoku.ac.jp. 